\title{
A Review of Fused Deposition Modeled Sacrificial Patterns in Investment Casting
}

\author{
Winston Sealy, Ph.D. \\ Minnesota State University, Mankato, Minnesota U.S.A. winston.sealy@mnsu.edu
}

\begin{abstract}
Over the years, investment casting methods have remained unchanged for the most part. Wax sacrificial patterns are invested to create voids for pouring metal parts. Nowadays, manufacturers are constantly seeking methods of lowering overall costs while sustaining or improving quality through continuous improvement activities. As such, additive manufacturing techniques continue to show promising results especially in investment casting applications. This paper provides an overview of recent research, highlighting the benefits and challenges of a variety of additive manufacturing techniques in investment casting. Moreover, specific examples of fused deposition modeled sacrificial pattern studies validating successful applications in investment casting are presented.

Keywords-Additive Manufacturing, Investment Casting,

Fused Deposition Modelling, Sacrificial Patterns, Rapid

Prototyping.
\end{abstract}

Digital Object Identifier (DOI):

http://dx.doi.org/10.18687/LACCEI2016.1.1.068

ISBN: 978-0-9822896-9-3

ISSN: 2414-6390

$14^{\text {th }}$ LACCEI International Multi-Conference for Engineering, Education, and Technology: "Engineering Innovations for Global Sustainability", 20-22 July 2016, San José, Costa Rica. 


\title{
A Review of Fused Deposition Modeled Sacrificial Patterns in Investment Casting
}

\author{
Winston Sealy, Ph.D. \\ Minnesota State University, Mankato, Minnesota U.S.A. winston.sealy@mnsu.edu
}

\begin{abstract}
Over the years, investment casting methods have remained unchanged for the most part. Wax sacrificial patterns are invested to create voids for pouring metal parts. Nowadays, manufacturers are constantly seeking methods of lowering overall costs while sustaining or improving quality through continuous improvement activities. As such, additive manufacturing techniques continue to show promising results especially in investment casting applications. This paper provides an overview of recent research, highlighting the benefits and challenges of a variety of additive manufacturing techniques in investment casting. Moreover, specific examples of fused deposition modeled sacrificial pattern studies validating successful applications in investment casting are presented.
\end{abstract}

Keywords-Additive Manufacturing, Investment Casting, Fused Deposition Modeling, Sacrificial Patterns, Rapid Prototyping.

\section{INTRODUCTION}

Traditional investment casting processes consists of tooling used to create wax sacrificial patterns. The tooling stage is tedious, time consuming, and on average demands $4-$ 6 weeks of precise machining. Although overall costs vary, Winker [1] estimates costs can range from $\$ 3,000$ to $\$ 30,000$ per tool. In addition, Cheah et al. [2] proposes the tooling stage typically ranges from 6 to 14 weeks. Tooling, therefore, is economical for large batch sizes as costs reductions are realized through economies of scale. For the most part, costs could be recouped from multiple uses of tools. Small batch production, on the other hand, become challenging to some manufacturers utilizing traditional investment casting methods. The costs of inflexibility and expensive tooling are usually transferred directly to the customer or end user. In a study conducted by Dickens and Hopkinson [3], the results of comparing three additive manufacturing technologies as alternatives to traditional investment casting tooling recommended additive manufacturing to be more economical than traditional investment casting tooling for production quantities in the thousands. In the study, a small lever $(\sim 1.4$ inch) and a medium sized cover ( $\sim$ inch) were casted using a wax injection molding tool and compared to Stereolithography Apparatus (SLA), Fused Deposition Modelling (FDM) and Selective Laser Sintering (SLS) technologies. For the lever with volumes greater than 14000 , traditional methods were cited as more economical. Likewise, the study favored the traditional method of tooling for the medium sized cover part for volumes greater than 700 units. However, small parts of unit volumes less than 14000 and medium parts less than 700 units resulted in substantial cost savings when additive manufacturing techniques were employed. According to the researchers, significant cost reductions of up to 6 folds were realized.

Moreover, Chhabra and Singh [4] have identified the following limitations to traditional investment casting tooling:

- Production of metal tooling for sacrificial patterns can lead to cost justification problems regarding prototyping, pre-series, customized and single, small and medium quantity production.

- Metal tooling consumes a substantial portion of the lead time.

- Costs and lead time increases due to tool design iterations.

Fig. 1, provides a graphical illustration comparing traditional investments casting processes to investment casting utilizing additive manufacturing techniques. As illustrated, additive manufacturing techniques eliminates costly and time consuming tooling resulting in a significant reduction of the pre-shell stage. More importantly, the use of additive manufacturing techniques in investment casting allows for greater flexibilities, especially for small or customized production.
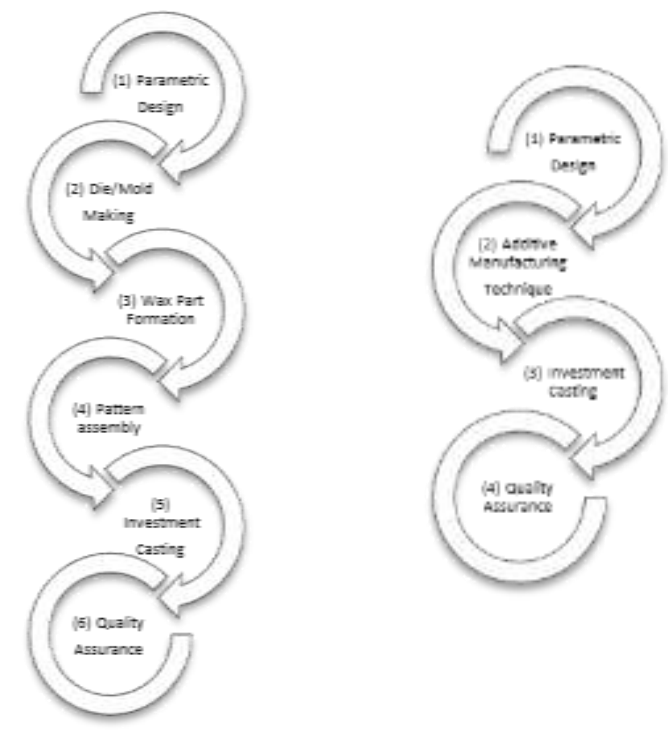

Fig. 1 Traditional Investment Casting vs. Additive Manufacturing Techniques

Digital Object Identifier (DOI): http://dx.doi.org/10.18687/LACCEI2016.1.1.068 ISBN: 978-0-9822896-9-3

ISSN: 2414-6390

$14^{\text {th }}$ LACCEI International Multi-Conference for Engineering, Education, and Technology: "Engineering Innovations for Global Sustainability", 20-22 July 2016, San José, Costa Rica. 


\section{INVESTMENT CASTING PROCESS}

Investment casting is one of the oldest casting processes (Fig. 2). Early civilizations used beeswax and clay molds to form various metals. Although investment casting is common in the jewelry and dentistry industries, after World War II, the process was adopted by the industrialized world to form metals for product development.

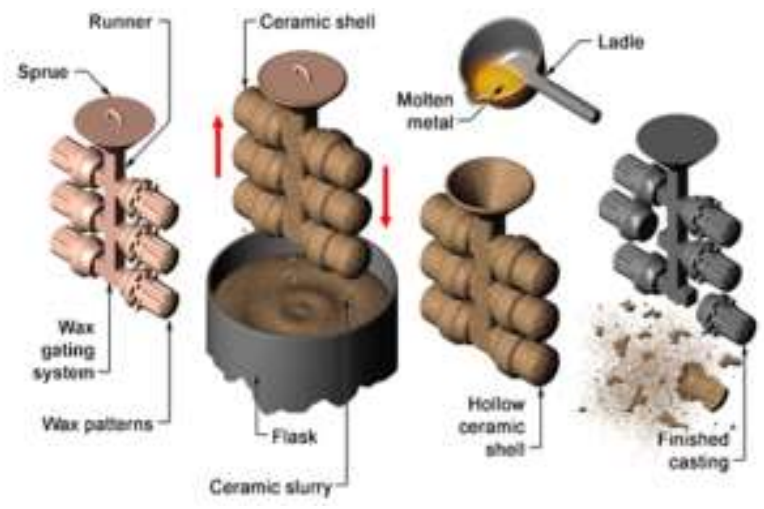

Fig. 2 Investment Casting Process.

(Extracted from:

http://www.ddgrinding.com/wpcontent/uploads/2011/

06/investment-casting.png)

The Investment casting process begins with the design and manufacture of a mold or die (Fig. 3). The mold is an outer cavity form of the part. Molds are commonly made by a machining specialist out of aluminum. Molten wax poured into the mold solidifies to the shape. For increased efficiencies, wax patterns are attached to a runner and sprue assembly. A ceramic shell is grown by dipping the assembly into a combination of ceramic slurry and fine sand. The ceramic thickness is achieved by the number of layers applied. After the slurry is fully formed and dried, the wax is melted and the assembly fully cured. Molten metal is then poured into the cavity and allowed to solidify. The application of porous slurry material allows gasses to be dissipated during metal solidification. This eliminates the buildup of hotspots caused by gases. The ceramic shell is removed through a combination of vibrations and chiseling. The final steps involve separating the parts by sawing and then applying finishing procedures.

\section{RELATED RESEARCH}

A review of the literature showcased a number of successful studies employing non-wax sacrificial patterns for investment casting applications. Dotchev and Soe [5] investigated CastForm using SLS technologies, Yao [6] studied SLA technology during his doctoral research, and

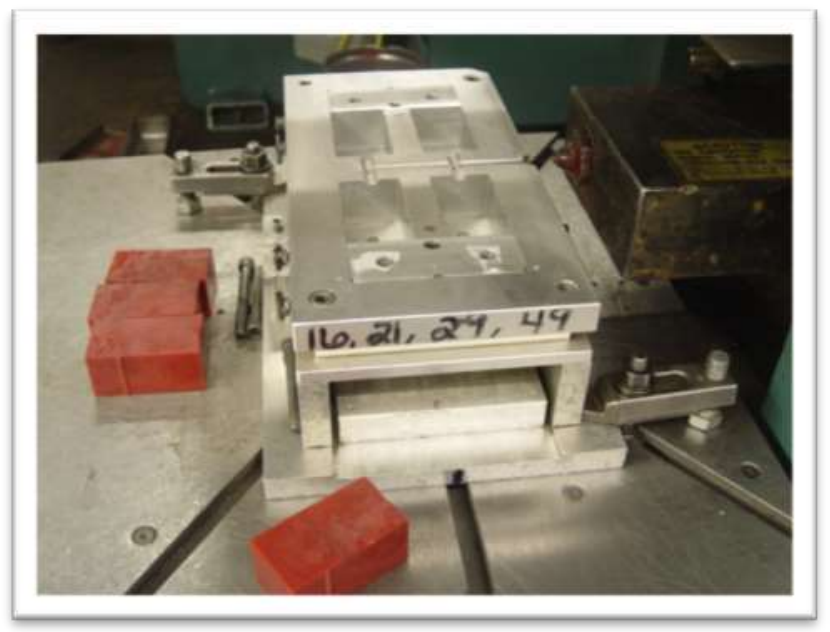

Fig. 3 Aluminium Mold

Qingbin et al. [7] developed a novel technology investigating rapid freeze prototyping. FDM technology has also been heavily researched by Blake and Gouldsen [8], Grimm [9], Cheah et al. [2], Harun et al. [10], and Singh et al. [11]. Although many detailed studies have been conducted on various additive manufacturing technologies, such as SLA, SLS, and Laminated Object Manufacturing (LOM), FDM technology has been documented as one of the cleanest technologies. Burnout of Acrylonitrile Butadiene Styrene (ABS) material produced no toxicity especially when compared to materials such as epoxy and polycarbonate. The literature highlighted some significant research of FDM applications in investment casting.

While additive manufacturing rapid repoductive systems provide significant bennefits for investment casting applications, non-wax materials still poses the challenge of shell cracking, incomplete burnout and residual ash. A mismatch of the coefficient of thermal expansion between the non-wax sacrificial pattern and ceramic shell leads to inconsistent expansion of the two materials. In turn, thermal stresses are induced on the ceramic shell that creates fractures. Granting their effects can be minimized through various techniques in design and processing, the risk still exist.

Wax patterns are sensitive to environmental conditions and are not ideal for thin wall castings. As a result, any additive manufacturing generated component that can be flashed fired without damaging the ceramic shell can be used as a substitute of wax investment casting pattern [4]. Although many studies have shown that in selecting non-wax patterns, problems such as, shell cracking, incomplete burnout and residual ash, should be avoided, non-wax patterns allows finishing operations that can drastically improve surface quality of finished products. Non-wax patterns have two significant advantages over wax patterns [2]. Firstly, the durability and strength allow for thinner walls and more

$14^{\text {th }}$ LACCEI International Multi-Conference for Engineering, Education, and Technology: "Engineering Innovations for 
intricate design options. Secondly, finishing operations can be easily applied to improve surface quality and finish.

Despite the fact that a number of additive manufacturing technologies can be used for either mold or sacrificial patterns in investment casting, this study only investigates FDM additive manufacturing techniques for the creation of thin walled sacrificial patterns. In addition, additive manufacturing techniques such as FDM provides the benefits of small and complex parts due to the independence of geometry $[12,13$, 14,15]. According to the literature, it is established by a number of studies that shell failure is an inherent problem when using non-wax sacrificial patterns. The problem occurs due to thermal expansion of the sacrificial pattern during burnout. Jacobs [16] suggests using the QuickCast technique developed by 3D Systems as a possible workaround. QuickCast replaces solid geometries with triangular shells. As a result, the hollow sacrificial pattern melts and collapses inwards eliminating thermal stresses due to expansion [17].

\section{ADDITIVE MANUFACTURED WAX PATTERNS}

One direct application of additive manufacturing systems in investment casting involves systems that utilize wax materials. 3D system's Thermojet, for example, is capable of building direct wax sacrificial patterns. Since the wax material is similar to traditional investment casting wax, little change is required to the process.

3D printing and SLS technologies utilize an infiltration process for investment casting. A starch-based material used in $3 \mathrm{D}$ printing is infiltrated with wax then assembled on a runner and sprue for shelling. Similarly, SLS builds with a polystyrene material that is also infiltrated with wax prior to assembly. CastForm, developed by 3D Systems, builds polystyrene parts through laser sintering. For casting, the green polystyrene part is treated in a wax infiltration process.

Many studies have been conducted on the CastForm process. Dotchev and Soe [5], for example, concluded that the weakest link of the CastForm process involved the infiltration of wax into the green part. Since the green part is so fragile, cleaning and movement should be limited and performed with extreme care. The main principle is not to move or touch the green part during wax infiltration when the material strength is minimal [5]. Current practices of wax infiltration involve manual processes, where, the green part is submerged into a vat of wax or the wax in poured over the part. Consequently, the wax infiltration process can produce inconsistencies that are difficult to control. For the most part, the cooling rate of wax must be controlled, as inconsistent or rapid cooling can damage the green part, particularly thin walled features.

\section{ADDITIVE MANUFACTURED NON-WAX PATTERNS}

Yao [6] in his dissertation research investigated SLA technology for building sacrificial investment casted patterns. Since non-wax materials induces thermal stresses capable of shell cracking during the burnout process, Yao's experimental study, investigated conditions that were attributable to shell failure. In the study a Finite Element Analysis (FEA) was conducted to determine induced shell stresses which were further verified experimentally. The study explored three patterns of the QuickCast technique. Hexagonal, triangular and square web structures were investigated and compared. The hexagonal structure performed best compared to the triangular and square structures with reduced stresses of $32 \%$ and $22 \%$ respectively [6].

Table 1, summarizes the accuracy, transferability and toxicity of some common additive manufacturing technologies. Thermoplastics and casting wax were classified as non-toxic in FDM and SPI technologies. Although SLA technologies exhibited excellent accuracies, the epoxy material measured toxicity during burnout. Yao [6] demonstrated casting wax and low melting thermoplastics produced no toxicity of both FDM and SPI technologies.

Table 1 Compatibility of RP processes with investment casting

\begin{tabular}{lllll}
\hline $\begin{array}{l}\text { RP } \\
\text { Process }\end{array}$ & Material & Accuracy & Transferability & $\begin{array}{l}\text { Material } \\
\text { Toxicity }\end{array}$ \\
\hline SLA & Epoxy & Excellent & $\begin{array}{l}\text { Thermal } \\
\text { expansion } \\
\text { Material } \\
\text { shrinkage }\end{array}$ & yes \\
SLS & $\begin{array}{l}\text { Casting wax, } \\
\text { polycarbonate }\end{array}$ & Poor & yes \\
FDM & Casting wax & Good & $\begin{array}{l}\text { Similar to } \\
\text { "Lost wax" }\end{array}$ & No \\
SPI, & $\begin{array}{l}\text { Low melting } \\
\text { MODEL }\end{array}$ & Excellent & $\begin{array}{l}\text { Negligible } \\
\text { Thermal } \\
\text { expansion } \\
\text { MAKER }\end{array}$ & No \\
DSPC & $\begin{array}{l}\text { Casting } \\
\text { ceramic }\end{array}$ & Poor & $\begin{array}{l}\text { Material } \\
\text { shrinkage } \\
\text { Residual ash }\end{array}$ & Yes \\
LOM & Sheet paper & Fair & Yes \\
\hline
\end{tabular}

Qingbin et al. [7] investigated a rapid freeze prototyping system for manufacturing investment casted parts utilizing water. Two experiments were conducted to demonstrate the viability of the process. The first experiment examined two critical factors of additive manufacturing, namely, surface finish and dimensional accuracy. The second experiment reviewed and compared ice sacrificial patterns to traditional wax patterns. 


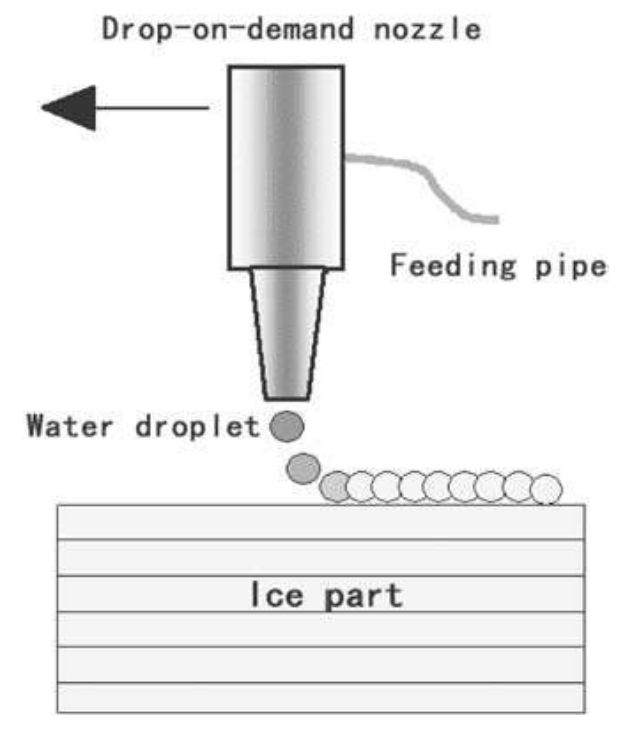

Fig. 4 Rapid Freeze Principle [7]

The rapid freeze prototyping system builds $3 \mathrm{D}$ ice parts directly from CAD (Fig. 4). The water in the feeding pipe is ejected drop by drop in a drop-on-demand mode. The build environment is kept at a temperature below water's freezing point. Pure water or colorized water is ejected from the nozzle and deposited onto the substrate or the previously solidified ice surface. In the process, water droplets do not solidify immediately. Instead, they spread and unite together to become part of a continuous water line. The newly deposited water is cooled by the low temperature environment through convection and by the previously formed ice layer through conduction. After a layer is finished, the nozzle is elevated upwards the height of one layer thickness. After a predetermined delay, for solidification, the next layer begins. This procedure continues until the designed ice part has been fabricated.

Advantages of rapid freeze prototyping include:

- Cheap and clean process

- Decreased likelihood of investment shell cracking as compared to wax patterns

- Makes ice patterns directly from CAD models in a short time, without the high cost and other issues of mold making of metal castings

Dimensional accuracy and surface finish were measured for 12 casted cylinders of diameter $7.62 \mathrm{~mm}(0.3$ ") and height $8.128 \mathrm{~mm}(0.32$ "). The results of the study indicated that the dimensional accuracy of wax investment casted parts had better accuracy than ice patterns, however, castings from ice patterns displayed better surface finish. The poor dimensional accuracy was attributed to the interface agent used to seal the ice prior to shelling, along with the effects of firing.

\section{FDM APPLICATIONS}

FDM sacrificial patterns resulted in cleaner burn-out, more robust, and less fragile, when compared to other additive manufacturing investment casting processes [8]. The study consisted of casted ABS FDM parts from six foundries. The test part consisted of a wedge design. The design allowed for measurements of part accuracy and determination of shrinkages. The average shrinkage result for one foundry is recorded as $0.76 \%$ (Table 2). Furthermore, the experiment demonstrated that at approximately $212^{\circ} \mathrm{F}$ during the burnout phase of the ABS sacrificial pattern, the average expansion was maximized at $0.35 \%$. Thereafter, melting occurred at approximately $257^{\circ} \mathrm{F}$. The report further demonstrated that hollow parts improved efficiencies with quicker builds and less mass to burn-out. Although shrinkages varied slightly amongst foundries due to differences in methods and processes, ABS sacrificial pattern expansion of $0.35 \%$ or less did not demonstrate ceramic shell fractures [8].

Table 2 Average Shrinkage Measurements [8]

\begin{tabular}{|c|c|c|c|c|c|}
\hline $\begin{array}{c}\text { Dimension } \\
\text { ID } \\
\end{array}$ & $\begin{array}{l}\text { Drawing } \\
\text { dimension }\end{array}$ & $\begin{array}{l}\text { Average RP } \\
\text { dimension (ABS) }\end{array}$ & $\begin{array}{l}\text { Average casting } \\
\text { dimension (alu) }\end{array}$ & Deviation & $\%$ shrink \\
\hline 1 & 4 & 3.999 & 3.990 & 0.009 & 0.23 \\
\hline 2 & 1,13 & 1.123 & 1.103 & 0.020 & 1.76 \\
\hline 3 & 0.75 & 0.731 & b.743 & -0.012 & -1.62 \\
\hline 4 & 1.25 & 1.242 & 1.228 & p.o14 & 1.11 \\
\hline 5 & 2.75 & 2.747 & 2.739 & $p .008$ & 0.30 \\
\hline 6 & 1.75 & 1.748 & 1.742 & $p .006$ & 0.34 \\
\hline 7 & 1 & 1.000 & 0.993 & 0.007 & 0.70 \\
\hline 8 & 1 & b997 & 1.014 & 0.017 & -1.71 \\
\hline 9 & b.75 & b.745 & 0.742 & p.004 & b.50 \\
\hline 10 & 0.375 & b. 372 & 0.369 & 0.003 & 0.87 \\
\hline 11 & 0.25 & 0.249 & 0.241 & b.009 & 3.41 \\
\hline 12 & b.25 & 0.247 & 0.239 & p.008 & 3.34 \\
\hline 13 & b. 75 & 0.746 & 0.737 & 0.009 & 1.24 \\
\hline 14 & b.68 & 0.678 & 0.874 & b.004 & 0.55 \\
\hline 15 & 0.115 & 0.114 & 0.113 & p.001 & 1.09 \\
\hline 16 & 2.5 & 2498 & 2.170 & p.028 & 1.12 \\
\hline 17 & p.s & 0.510 & 0.505 & p.005 & 0.93 \\
\hline 18 & $h$ & b.994 & 0.991 & 0.003 & b. 30 \\
\hline \multicolumn{4}{|r|}{ Average } & 0.005 & 0.76 \\
\hline
\end{tabular}

Rapid Prototyping has provided the advantage to manufacturers of cost effective short runs with economic order quantities as low as one [9]. In an experimental evaluation study of three FDM, one SLS and SLA systems, Grimm [9] concluded that although surface finish is a limitation for FDM when compared to other additive manufacturing technologies, such as SLS and SLA, FDM patterns were more suitable for investment casting applications, with little modification to the

$14^{\text {th }}$ LACCEI International Multi-Conference for Engineering, Education, and Technology: "Engineering Innovations for 
standard foundry process. In the experimental study, twelve linear dimensions were measured and compared to nominal values. The dimensions ranging from $2.54 \mathrm{~mm}(0.1$ ") to 152.4 $\mathrm{mm}$ (6") measured an average deviation of $0.6 \%$ from nominal. The largest deviation was measured along the $\mathrm{z}$-axis $(2.05 \%)$. Surface finishes were best on the side walls (parallel to $\mathrm{z}$-axis), with an average value of $437.5 \mu \mathrm{in}$. The bottom surface measured the worst due to contact with the base material. Bottom and top surface finishes measured $562.5 \mu$ in and $512.5 \mu$ in respectively. Even with the limitation of surface finish, Grimm [9] demonstrated that ABS material can be finished to achieve significant improvements of approximately $83 \%$ surface improvement. One key advantage of FDM over SLA is that of dimensional stability. According to the study, time and environmental exposure alters the dimensions on parts built with an SLA process. Even after SLA parts are allowed to settle at room temperature the size of features can change. Unlike SLA, FDM dimension remains fixed and on average more robust to time and minor environmental changes.

Through collaborative research between the Universiti Teknologi Malaysia and Universiti Malaysia Pahang, Harun, Idris and Sharif summarized the following [18]:

- Surface roughness is consistent for both hollow and solid pattern construction

- Hollow patterns had better dimensional accuracies compared to solid patterns

- Hollow patterns exhibited greater distortion (33.11\%) than solid patterns

- Hollow patterns did not cause shell cracking during all investigated burning temperatures as compared to solid patterns

The research consisted of designing and printing four solid and four hollow patterns using FDM technology. The patterns were evaluated and compared for dimensional accuracy, surface finish and distortion. Following printing, the patterns were shelled then burned at temperatures ranging from $300^{\circ} \mathrm{C}$ to $600^{\circ} \mathrm{C}$. Twenty-six dimensions were measured to an accuracy of $1 \mu \mathrm{m}$. During the burnout process, a digital weighing machine was used to measure the weight loss of the pattern as the temperature increased from $300^{\circ} \mathrm{C}$ to $600^{\circ} \mathrm{C}$. For each temperature increment, the patterns were baked for 1 hour then left to cool for 12 hours. Although no cracking was observed on the hollow shell throughout the experiment, at temperatures ranging from $300^{\circ} \mathrm{C}$ to $500^{\circ} \mathrm{C}$ there were visible signs of cracking on the solid shell. The study also demonstrated that there was no shell cracking of the solid pattern for temperatures of $550^{\circ} \mathrm{C}$ to $600^{\circ} \mathrm{C}$ [18]. "In the range of $200^{\circ} \mathrm{C}$ to $300^{\circ} \mathrm{C}$ it gets softened and become paste... above $570^{\circ} \mathrm{C}$ ABS turns into ash" [11]. The researchers attributed cracking of the solid shell to thermal expansion stresses exerted on the ceramic shell.
Table 3, summarizes the accuracy results of research conducted by Cooper and Wells [19] in evaluating rapid prototyping applications for investment casting at the Marshall Space Flight Center. In an experimental study of casting six fuel pump models, a range of additive manufacturing technologies were utilized to determine dimensional accuracy. In addition, surface finishes for SLS, FDM, LOM, and Z-Corp were measured at $200 \mu \mathrm{in}, 60 \mu \mathrm{in}, 60 \mu \mathrm{in}$, and $300 \mu \mathrm{in}$, respectively.

Table 3 SLS, FDM, LOM, Z-CORP Dimensional Results [19]

\begin{tabular}{|l|c|c|c|c|c|c|}
\hline FDM-ABS & $x$ Accuracy & $\boldsymbol{y}$ Aceuracy & $\boldsymbol{z}$ Accuracy & $\boldsymbol{x}$ Per Inch & $\boldsymbol{y}$ Per Inch & $\boldsymbol{z}$ Per Inch \\
\hline CAD-RP & 0.0068 & 0.0003 & 0.0035 & 0.0015 & 0.0000 & 0.0008 \\
RP-Casting & 0.0055 & 0.0125 & -0.0116 & 0.0012 & 0.0020 & -0.0027 \\
CAD-Casting & 0.0132 & 0.0128 & -0.0081 & 0.0028 & 0.0021 & -0.0019 \\
\hline \hline LOM & $x$ Accuracy & $\boldsymbol{y}$ Accuracy & $\boldsymbol{z}$ Accuracy & $\boldsymbol{x}$ Per Inch & $\boldsymbol{y}$ Per Inch & $\boldsymbol{z}$ Per Inch \\
\hline CAD-RP & 0.0130 & -0.0113 & -0.0293 & 0.0028 & -0.0018 & -0.0069 \\
RP-Casting & 0.0003 & 0.0300 & 0.0286 & 0.0001 & 0.0049 & 0.0067 \\
CAD-Casting & 0.0132 & 0.0187 & -0.0006 & 0.0028 & 0.0031 & -0.0001 \\
\hline \hline Z-Corp & $\boldsymbol{x}$ Accuracy & $\boldsymbol{y}$ Accuracy & $\boldsymbol{z}$ Accuracy & $\boldsymbol{x}$ Per Inch & $\boldsymbol{y}$ Per Inch & $\boldsymbol{z}$ Per Inch \\
\hline CAD-RP & 0.0065 & -0.0085 & 0.0142 & 0.0014 & -0.0014 & 0.0033 \\
RP-Casting & 0.0142 & 0.0349 & 0.0400 & 0.0030 & 0.0057 & 0.0094 \\
CAD-Casting & 0.0207 & 0.0264 & 0.0543 & 0.0044 & 0.0043 & 0.0127 \\
\hline SLS-Polycarb & $\boldsymbol{x}$ Accuracy & $\boldsymbol{y}$ Accuracy & $\boldsymbol{z}$ Accuracy & $\boldsymbol{x}$ Per Inch & $\boldsymbol{y}$ Per Inch & $\boldsymbol{z}$ Per Inch \\
\hline CAD-RP & -0.0105 & -0.0090 & 0.0032 & -0.0022 & -0.0015 & 0.0008 \\
RP-Casting & 0.0439 & 0.0301 & 0.0496 & 0.0094 & 0.0049 & 0.0116 \\
CAD-Casting & 0.0334 & 0.0211 & 0.0529 & 0.0071 & 0.0034 & 0.0124 \\
\hline
\end{tabular}

Another survey of applications for investment casting using additive manufacturing rapid reproductive systems, Cheah et al. [2] reviewed both mold and direct pattern fabrication. The survey summarized that dimensional accuracy, surface quality and part durability must be further investigated and improved. Shrinkage compensation factors, post machining allowances and foundry requirements were critical pre-requisites that also must be considered for improving quality.

\section{EXPERIMENTAL VALIDATION}

A number of experimental studies involving both academia and industry supports and have successfully demonstrated the use of non-wax materials, such as ABS, for sacrificial patterns in investment casting applications. According to Blake and Gouldsen's [8] comprehensive study involving six foundries, the maximum thermal expansion of fused deposition ABS sacrificial patterns was .35\%. The study consisted of building ABS patterns utilizing FDM technology for mechanical and thermal property testing. Thin walled test parts of thicknesses .025", .035", .04", .05", .07", and .1" were supplied to six different foundries for casting. The burnout sequences for three foundries are recorded in table 4 . 
Table 4 Burn-out sequences from three foundries [8]

\begin{tabular}{|c|l|l|l|l|}
\hline Foundry & $\begin{array}{l}\text { Pre-heat \& } \\
\text { load }\end{array}$ & Ramp to: & Hold & Cooling \\
\hline $\mathrm{A}$ & $\begin{array}{l}1600^{\circ} \mathrm{F} \\
\left(871^{\circ} \mathrm{C}\right)\end{array}$ & $\begin{array}{l}1950^{\circ} \mathrm{F} \\
\left(1066^{\circ} \mathrm{C}\right)\end{array}$ & $\begin{array}{l}1.5-2 \\
\text { hr. }\end{array}$ & $\begin{array}{l}\text { Natural } \\
\text { over night }\end{array}$ \\
\hline B & $\begin{array}{l}1600^{\circ} \mathrm{F} \\
\left(871^{\circ} \mathrm{C}\right) \\
\text { for } \\
\text { minutes }\end{array}$ & $\begin{array}{l}2050^{\circ} \mathrm{F} \\
\left(1120^{\circ} \mathrm{C}\right)\end{array}$ & $\begin{array}{l}50 \\
\text { mins. }\end{array}$ & $\begin{array}{l}1600^{\circ} \mathrm{F} \\
\left(871^{\circ} \mathrm{C}\right) \\
\text { remove to } \\
\text { cool }\end{array}$ \\
\hline $\mathrm{C}$ & Ambient & $\begin{array}{l}1800^{\circ} \mathrm{F} \\
\left(982^{\circ} \mathrm{C}\right)\end{array}$ & $3 \mathrm{hr}$. & $\begin{array}{l}\text { Natural } \\
\text { over night }\end{array}$ \\
\hline
\end{tabular}

Thermal expansion and decomposition were measured using a dilatometer and thermo gravimetric analysis respectively. The dilatometer recorded a maximum of $.35 \%$ linear expansion at $356^{\circ} \mathrm{F}$ with an average of $.24 \%$ linear expansion at a temperature of $352^{\circ} \mathrm{F}$. It was also noted that ABS reached a softening point where expansion declined between $221^{\circ} \mathrm{F}$ and $352^{\circ} \mathrm{F}$. At temperatures between 572 and $752^{\circ} \mathrm{F}, 95 \%$ burnout of a $4 \mathrm{oz}$ sample was achieved. The study further notes that the remaining material burned off at $1067^{\circ} \mathrm{F}$. The experimental study demonstrated that FDM sacrificial patterns that are built from ABS material are suitable for investment casting applications. Each foundry was capable of producing acceptable investment castings. All in all, ABS sacrificial patterns produced clean burn-out and robustness for better handling.

Singh et al. [11] in an experimental study comparing sacrificial patterns of FDM and SLS technologies, agreed with Blake and Gouldsen [8] thermal expansion of $.35 \%$. In their experimental study, $12 \mathrm{~mm}$ ABS cubes were measured for thermal expansion using a dilatometer. The results of the test were identical to Blake and Gouldsen [8] ABS thermal expansion of $.35 \%$. The study also involved the worthiness of $\mathrm{ABS}$ as a sacrificial pattern, behavior of ABS during burnout and castability. ABS started softening above $302^{\circ} \mathrm{F}$ and burned between $572^{\circ} \mathrm{F}$ and $842^{\circ} \mathrm{F}$. Similar to Blake and Gouldsen [8], total burnout was achieved at approximately $1058^{\circ} \mathrm{F}$. Furthermore, recent studies conducted at Missouri University of Science and Technology and Virginia Tech supports and demonstrate the successful application of ABS sacrificial patterns for investment casting.

\section{CONCLUSION}

Even with the variety of additive manufacturing technologies used for investment casting applications, there was no clear evidence as to which technology was most beneficial. However, additive manufactured sacrificial patterns, can be created directed from CAD, eliminating costly and time consuming tooling for investment casting. Moreover, non-wax sacrificial patterns can also be integrated into existing investment casting processes with little hassle or modifications. The research also demonstrated that FDM sacrificial patterns exhibited clean burnout and with geometry design techniques can eliminate shell fracture generated by thermal expansion.

[1] Winker, R. (2010). Investment Casting. Stratasys Inc. http://www.dimensionprinting.com/3d-printers/printingproductspecs 1200 series.aspx

[2] Cheah, C. M., Chua, C. K., Lee, C. W., Feng, C. C., \& Totong, K. K. (2005). Rapid prototyping and tooling techniques: a review of applications for rapid investment casting. International Journal of Advanced Manufacturing Technology, 25(3/4), 308-320.

[3] Dickens, P., \& Hopkinson, N. (2003). Analysis of rapid manufacturingusing layer manufacturing processes for production. Proceedings of the Institution of Mechanical Engineers, Part C: Journal of Mechanical Engineering Science, 217(1), 31-39.

[4] Chhabra, M., \& Singh, R. (2011). Rapid casting solutions: a review. Rapid Prototyping Journal, 17(5), 328-350.

[5] Dotchev, K., \& Soe, S. (2006). Rapid manufacturing of patterns for investment casting: improvement of quality and success rate", Rapid Prototyping Journal, 12(3), 156-164

[6] Yao, W. (1998). Analytical and experimental study of investment casting with laser stereolithography models. New Jersey Institute of Technology).

[7] Qingbin, L., Leu, M.C., Richards, V. L., \& Schmitt, S. M. (2004). Dimensional accuracy and surface roughness of rapid freeze prototyping ice patterns and investment casting metal parts. International Journal of Advanced Manufacturing Technology, 24(7/8), 485-495.

[8] Blake, P., \& Gouldsen, C. (1998). Investment casting using FDM/ABS rapid prototype patterns, Trade report, USA

[9] Grimm, T. (2003). Fused Deposition Modelling: A Technology Evaluation. T.A. Grimm \& Associates

[10] Harun, W. S. W., Idris, M. H. \& Sharif, S. (2008). Evaluation of ABS patterns produced from FDM for investment casting process. Proceedings of the $9^{\text {th }}$ Asia Pacific Industrial Engineering \& Management Systems Conference.

[11] Singh, N.K., Sivadasan, M., \& Sood, A.K. (2012). Use of fused deposition modeling process in investment precision casting and risk of using selective laser sintering process. International Journal of Applied Research In Mechanical Engineering, 2(1).

[12] Bak, D. (2003). "Rapid prototyping or rapid production? 3D printing processes move industry towards the latter", Rapid Prototyping Journal, 23(4), 340-345

[13] Bourell D., Leu M., Rosen D. (2009). Roadmap for Additive Manufacturing; identifying the future of freeform processing

[14] Ramos, A.M., Relvas, C. and Simoes, J.A. (2003). "Vacuum casting with room temperature vulcanizing rubber and aluminum moulds for rapid manufacturing of quality parts: a comparative study", Rapid Prototyping Journal, 9(2), 111-115.

[15] Wang, W., Conley, J.G. and Stoll, H.W. (1999). "Rapid tooling for sand casting using laminated object manufacturing process", Rapid Prototyping Journal, 5(3), 134-140.

[16] Jacobs, P.F. (1993). "Stereolithography 1993: epoxy resins, improved accuracy \& investment casting", Proceedings of $4^{\text {th }}$ International Conference on Rapid Prototyping, Dyton, OH, 14-17 June, pp. 249-62

[17] Yao, W.L. and Leu, M. (1999). "Analysis of shell cracking in investment casting with laser stereolithography patterns", Rapid Prototyping Journal, 5(1), 12-20.

[18] Harun, W. S. W., Idris, M. H. \& Sharif, S. (2008). Evaluation of ABS patterns produced from FDM for investment casting process. Proceedings of the $9^{\text {th }}$ Asia Pacific Industrial Engineering \& Management Systems Conference.

[19] Copper, K.G., Wells, D. (2000). Application of Rapid Prototyping to the Investment Casting of Test Hardware.

14 ${ }^{\text {th }}$ LACCEI International Multi-Conference for Engineering, Education, and Technology: "Engineering Innovations for Global Sustainability", 20-22 July 2016, San José, Costa Rica. 